\title{
Discussion of Moral Hazard in the Taiwan's Short-Term Active Labor Market Policy
}

\author{
Wen-Chia Cheng, Chi-Hsin Wu* \\ Department of Labor Relations, National Chung Cheng University, Taiwan \\ Email: *osmond@mai12000.com.tw
}

How to cite this paper: Cheng, W.-C. and Wu, C.-H. (2016) Discussion of Moral Hazard in the Taiwan's Short-Term Active Labor Market Policy. Modern Economy, 7, 12511263.

http://dx.doi.org/10.4236/me.2016.711120

Received: June 7, 2016

Accepted: October 7, 2016

Published: October 10, 2016

Copyright $\odot 2016$ by authors and Scientific Research Publishing Inc. This work is licensed under the Creative Commons Attribution International License (CC BY 4.0).

http://creativecommons.org/licenses/by/4.0/

\begin{abstract}
The Diverse Employment Development Program is an important short-term active labor market policy implemented more than ten years in Taiwan. Most of the researches in the past all mentioned about its benefit, but there are still many literatures indicated the problems of manpower utilization in the units participating in the DEDP. This paper tries to discuss Moral Hazard, one of the important factors, in theoretical point of view. The authors use document analysis and in-depth interview to conduct the research, and try to inspect whether there is Moral Hazard existed in the units. After interviewing twelve organizations, located in Yunlin, Chiayi, and Tainan, the authors draw three conclusions as follows: 1) Moral Hazard in the organizations implementing the DEDP isn't obvious, and it won't affect the operation of the organization seriously. 2) The incidence of Moral Hazard may have a connection with the characteristic of an organization but little relevance to its property. 3) The timing to announce the staff retention roster may not affect the possibility that Moral Hazard happens to an organization, but the way to announce it may influence the possibility that Moral Hazard happens to an organization. The authors hope these three conclusions can assist the further research in the future.
\end{abstract}

\section{Keywords}

Diverse Employment Development Program, Moral Hazard

\section{Introduction}

The history of the Diverse Employment Development Program (DEDP) can be dated back to the "921 Earthquake-Food for Work" program launched by the Ministry of Labor (MOL, formerly the Council of Labor Affairs) to assist the victims in the 921 Earthquake in 1999. The program was expanded into the "Reconstruction Program of Employment" in 2000. When the unemployment rate rose everywhere in Taiwan in 
2001, the MOL put forward the "Sustainable Employment Program (SEP)" by combining the EU experience in promoting and developing the third-sector labor market with local experience in the "921 Earthquake-Food for Work" in 1999 and the "Reconstruction Program of Employment" in 2000 [1]. The SEP was further expanded into the DEDP in 2002, as the MOL hoped to build a platform to deepen the relationships between the non-governmental organizations and the government. The DEDP is used to subsidize those plans implanted by the civil organizations and the government, so as to retain local culture, create jobs, and promote the civil organizations into social enterprises one day. The programs proposed by the subsidized organizations must contain financial mechanisms, industrial development prospects, and most importantly the channels to hire the unemployed [2]. The DEDP can be divided into two types: the economic plans and the social plans [3].

Supervised by the MOL, the DEDP would mainly subsidize the civil organizations of personnel costs to the candidates assigned by the public employment service institutes and provide them with consultation service as well. According to statistics, the DEDP has so far subsidized more than 8000 plans to hire over 12,000 people [4].

The DEDP has succeeded in boosting employment opportunities and helping the non-profit organizations develop themselves by using the short-term human resources thus gained, which these organizations could not afford to hire in the past [5]. Nevertheless, most of the studies have also mentioned problems of manpower utilization in the units participating in the DEDP. According to Lan, et al. [2] and Wu et al. [6], one of the problems in the DEDP is that almost all the disadvantaged hired by the non-profit organizations think that the DEDP is a kind of government rescue or a short-term employment program, leading to their lack of motive to learn or finish their work.

In their assessment of the benefits brought in by the DEDP, Zhu and Tong [7], and the Liande Industry and Commerce Development Foundation [8] all mentioned that a few candidates had the incorrect ideas to cause trouble to the employers' organizational management. The phenomenon might further distort human resources utilization, forcing the employers to provide more training for the candidates. Just because the candidates regarded the DEDP as a short-term program under the regulations of retaining systems and Relative Subsidy systems, they changed their work attitude, performed worse than before or gave out lower productivity when they found that they would not be retained next year. This is considered a Moral Hazard problem in the DEDP.

A concept adopted from Economics, Moral Hazard is usually used to explain some certain economic behaviors. Borrowed by the insurance trade, the term Moral Hazard has been even more frequently heard nowadays than before to mean that when a person pursues his/her biggest benefit, he/she might take action to hurt others. In this paper, Moral Hazard is defined as the risk that as the candidates regard their work as a short-term job, and when they learn that they will not be retained the next year, they change their work performance, resulting in negative influence to the organization they are serving. 
The authors use document analysis and in-depth interview to conduct the research. ${ }^{1}$ Through reading a lot of literature about the DEDP and Moral Hazard, and interviewing twelve units in different industries located in Yunlin, Chiayi, and Tainan, the authors try to answer four questions as follows: 1) whether there is Moral Hazard in the units implementing the DEDP; 2) whether the problem will affect the operation of the units; 3) whether the timing and the way to announce the staff retention roster will bring out Moral Hazard from the candidates; and 4) whether the characteristic of the units will influence the possibility of Moral Hazard. At the end, the authors try to suggest some concrete and feasible proposals on human resources management to help the DEDP achieve its purposes more effectively.

\section{Literature Review}

\subsection{The Diverse Employment Development Program}

The Diverse Employment Development Program (DEDP) is one of the important policies of the MOL for relieving the unemployment problems. Its origin can be traced back to the 921 Earthquake in 2000. The MOL launched the "921 Earthquake-Food for Work" measure in emergency to help the victims overcome their basic needs of living in the rebuilding of their homestead. Because it was insufficient in assisting employment, the MOL strengthened the job training and the employment service, and also searched for every possible work opportunity. As a result, the Reconstruction Program of Employment came into being in 2000. The measure succeeded in transferring the unemployed from passively receiving the subsidy into actively working for payment. In addition to receiving rewards to stabilize their livelihood, the unemployed could also reestablish their confidence when working, relieve their pressure and crisis of unemployment, and decrease the impact of unemployment [1].

According to Lin et al., [1], with reference to the Reconstruction Program of Employment and the EU Third Sector and Employment experimental action, the MOL developed the third sector employment system and launched the Sustainable Employment Program in 2001, which broadened the service scope to the entire country. Under the SEP, the non-governmental organizations and government departments proposed employment promotion plans and hired the disadvantaged in priority. By creating job opportunities in the locality, the SEP both lowered the unemployment rate and promoted local development. The duration of the SEP is one year (from February 2001 to May 2002). With a fund of two billion NT dollars, the SEP approved 1391 plans and provided 29,770 job opportunities. According to the tracking records, the SEP's economic plans could retain about forty percent of employees, but the retaining rate of SEP's social plans was mere fifteen percent. Compared with the unemployment rate at that time, it seemed that the SEP failed to solve the unemployment problems. Thus, the MOL launched the DEDP by referring to the EU experience in the development of the third sector to promote employment and capitalizing on such local experiences as the "921 Earthquake-Food for Work" in 1999, the "Reconstruction Program of Employ-

${ }^{1}$ Please read the detail interview outline in Appendix. 
ment" in 2000 and the "Sustainable Employment Program" in 2001 [9].

The DEDP also adjusted its objects and contents along with the changes and the needs of external environment over the years. For example, when the Sustainable Employment Program was launched in 2001, it covered only the social plans and the economic plans, and the DEDP expanded the scope to include the enterprise plans in 2002, with a primary purpose to motivate the enterprises to hire more people and train their newly hired to gain direct work experience and skills, so that the unemployed could enforce their employability and would be retained even after the DEDP expires, achieving the goal of helping them reenter into the job market. In 2005, in addition to the non-governmental units, the DEDP was expanded again to include the government departments, making the planning groups include the first (government) sector, the second (enterprise) sector, and the third (non-governmental) sector [10]. In 2006, the DEDP added in the part-time working systems and extended the duration of social plans up to three years. In 2007, the Relative Subsidy systems were put forward to encourage the hiring organizations to retain the original staff [1]. So far the DEDP has been being implemented for more than ten years. Its implementation methods are adjusted along with the reviews and audits, result reports, and field evaluations every year. It is hoped that the DEDP can boost employment and regional development continuously and achieve the vision of diverse sustainable development [11].

\subsection{Contents and Retaining Design of the Diverse Employment Development Program}

The objectives of the Diverse Employment Development Program are to construct the partnership between the non-governmental organizations and the government departments, promote the social well-being and regional development, and create the local employment opportunities.

The DEDP can be divided into two types, i.e. economic plans and social plans, either of which has its own purposes and is governed by different regulations and subsidy systems. The economic plans are implemented by the non-governmental organizations to promote regional development and industrial prospects and offer job opportunities for the unemployed. The social plans are implemented by local and central governments or non-governmental organizations to promote social welfare and employment.

The DEDP subsidizes two types of targets, i.e. the candidates and the project managers (administrators). Qualifications are as follows: 1) The candidates: The unemployed must be recommended by the public employment service agencies and hired by the organizations. The public employment service agencies should check and file the hiring process, and agree with the starting work date. 2) The project managers (administrators): The hiring organizations are free to select their own project managers and then inform the public employment service agencies for record. However, the qualification of a project manager hired by a non-governmental organization must be examined by the public employment service agencies under the Bureau of Job Training before the project manager or administrator can be hired. 
Both the social plans and the economic plans under the DEDP are designed to subsidize the wages of the candidates and project managers in the hope to create local employment opportunities for those who have difficulty in being hired by the governmental or private sectors and in turn promote local industrial development and nongovernmental organizations.

According to Article 14-1-3 of the DEDP, a non-governmental organization that has implemented an economic or a social plan for three years can apply for the Relative Subsidy system, which regulates that if the non-governmental organization retains every one person from the original three-year plan, it will be entitled to receive wage subsidy for another newly hired in a sliding scale, which means that the wage subsidy is $100 \%$ for every newly hired in the first year but will be reduced to two-thirds of the previous year, so that the organization can gradually decrease its reliance on the subsidy and operate independently. As long as the hiring organization follows the Relative Subsidy regulations, the government will grant the subsidy. However, if a hired candidate quits the job during the plan, the organization has to find another substitute according to the rules.

The DEDP has so far been being implemented for more than ten years. It has increased employment opportunities for the disadvantaged, but there have been some difficulties and negative effects in the program, too, which can be summed up to Table 1 as follows.

\subsection{Moral Hazard}

There has been no consistent definition on Moral Hazard. Robert et al., [16] defines Moral Hazard as a phenomenon in which a person's behavior not directly accessible to observation may affect the frequency and scope of an incidence involving payment of money. Chen, and Lin [17] defines Moral Hazard as a result of information asymmetry, due to which one changes his/her behavior after a transaction and harms the interests of the other party. $\operatorname{Nan}^{2}$ (2011) defines Moral Hazard as a situation in which if someone is insulated from the risk, his/her behavior may be different from when he/she is exposed to the risk directly. When a person or an agency doesn't have to bear the result of his/her or its behavior, he/she or it may act carelessly and incautiously and have the third party bear the responsibility. That is how Moral Hazard comes up (Table 2).

\section{Analysis of Interview Results}

The authors have conducted in-depth interviews in a semi-structured way. The interview questionnaire is designed and outlined in advance and divided into two parts. The first part is the basic information of those twelve organizations, and the second part is about their human resource management. The research objects of the paper include managers of the DEDP or the person in charge of the hiring organizations in different industries located in Yunlin, Chiayi or Tainan. They are chosen through the purposive sampling method. To achieve the research purpose of diversification, the paper chooses

${ }^{2}$ Please read the article in the website: http://www.cw.com.tw/article/article.action?id=5000986. 
Table 1. Difficulties and negative effects of the diverse employment development program.

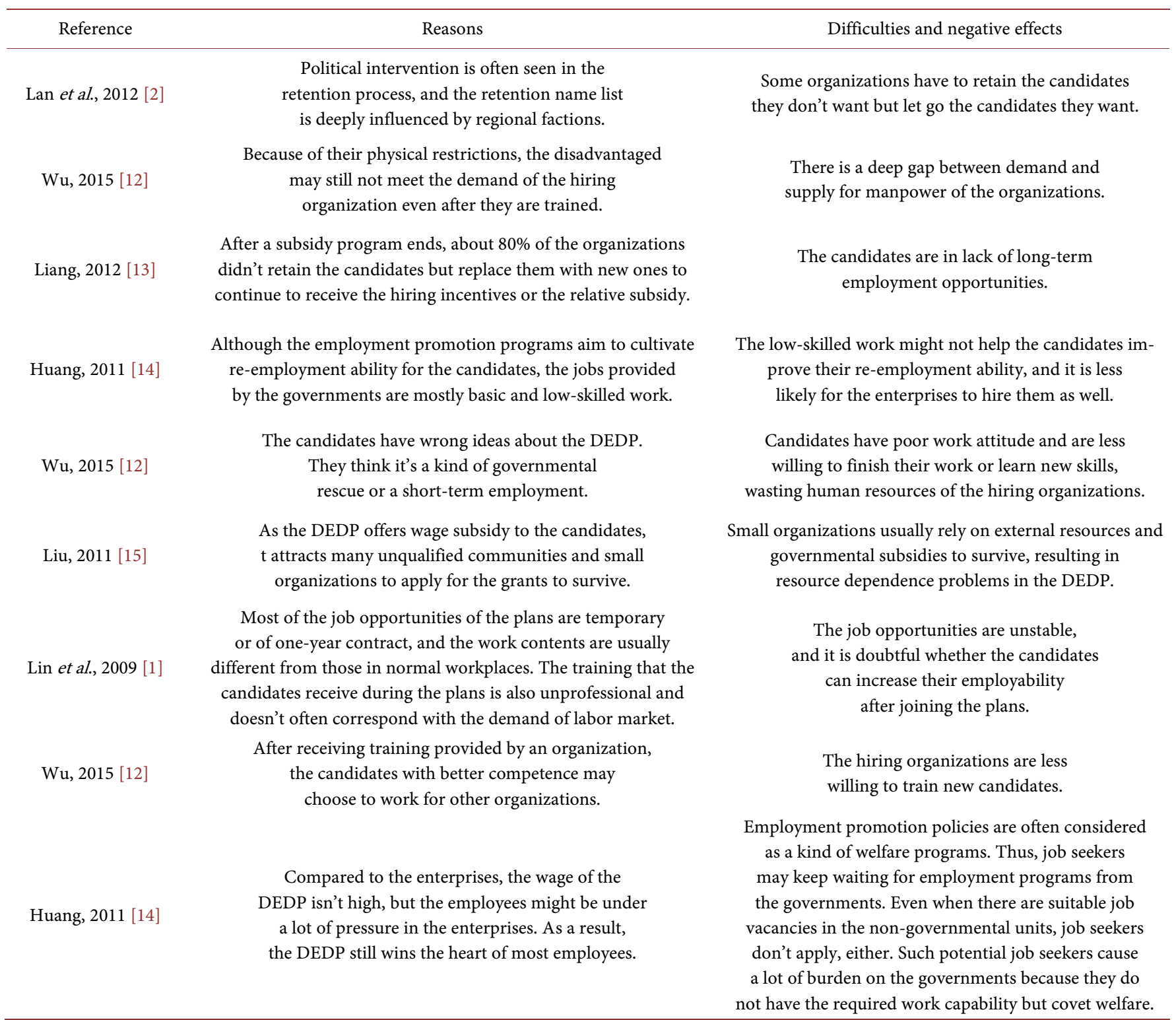

Resource: By the authors finishing.

both the organizations retaining more candidates and units in a variety of regions and industries.

Interview results are discussed in two parts, namely the internal environment and the external environment. The internal environment means the situations that the candidates can control to a certain extent by themselves. Such situations include whether the candidates try to guess or ask about the name list before the organization announces the staff retention roster and whether the candidates change their working performance after it is announced. Meanwhile, the external environment means such things controlled by the organization as the timing and the way to announce the staff retention roster, the observation period and the assessment before deciding the name list. 
Table 2. Common cases of moral hazard.

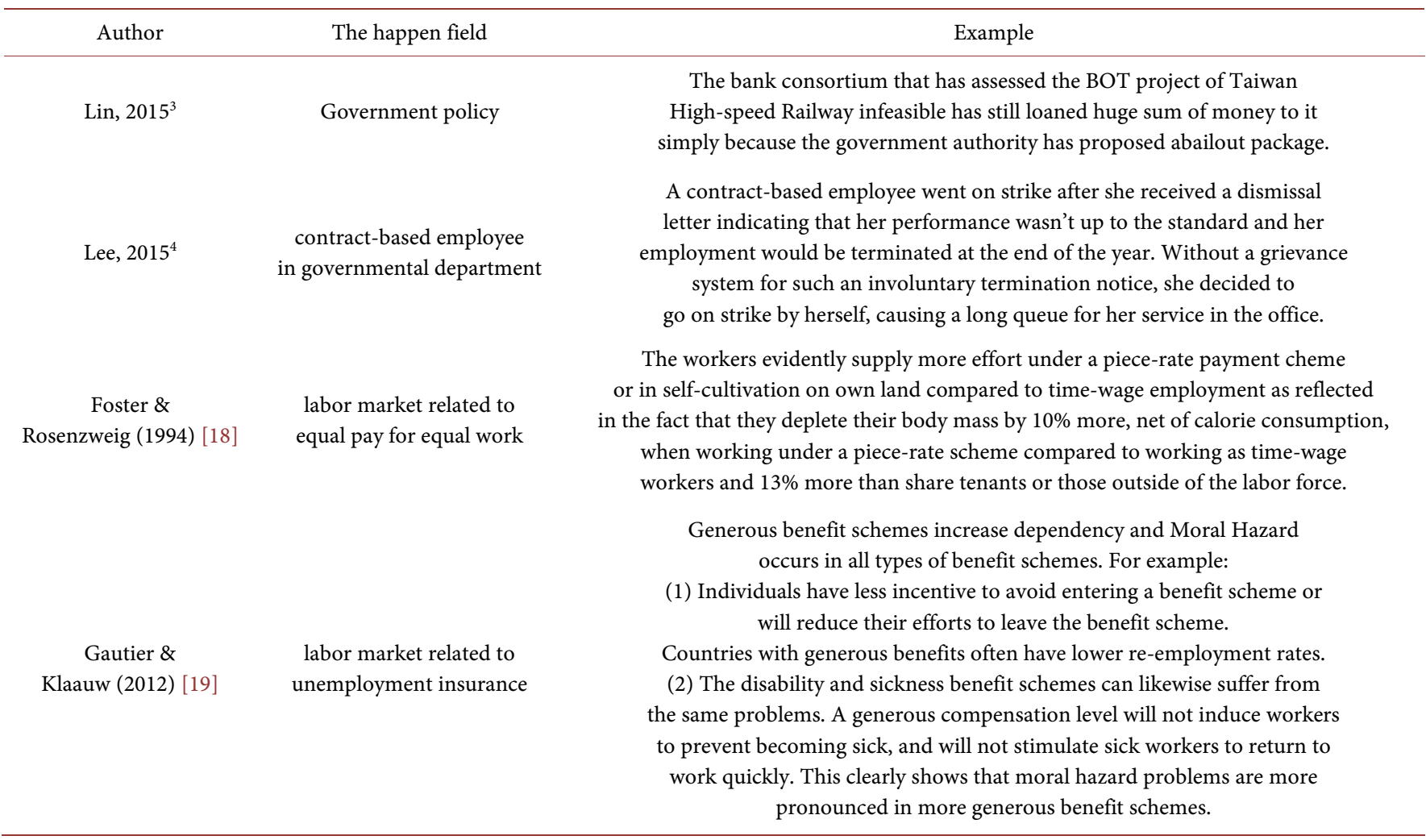

Resource: By the authors finishing.

\subsection{Internal Environment Analysis}

\subsubsection{Situations in Which Candidates Guess or Ask about the Staff Retention Roster}

Analysis of the interview results shows that such a situation exists in six different units but not in the rest of units. Three of those units with the name list probing situation indicate that most of the guesses happen at the mid- and late stage of the hiring plans. Two of the units with guessing problems indicate that most of the guesses and discussions happen only among the candidates themselves, but three units indicate that the candidates usually ask the project manager or the administrator about the staff retention roster. These two behaviors, however, happen in the sixth unit. Based on the above results, it's not difficult to find that no matter what kind of hiring plans the units apply for, guessing or asking about the staff retention roster is likely to happen.

\subsubsection{Changes of Attitude or Behaviors among Candidates Not Retained for the Next Year}

After announcing the staff retention roster, five different units indicated that their candidates didn't change their original behavior and work attitude, but four units indicated that their candidates consequently changed the behavior and work attitude. Two of

${ }^{3}$ Please read the news in the website: https://www.facebook.com/udnip/posts/852334041499765.

${ }^{4}$ Please read the webpage to see detail about the news:

http://www.appledaily.com.tw/realtimenews/article/new/20151224/760467/. 
these four units mentioned that the changes did not cause serious impact on their operation. Three units indicated that the retained candidates would even give up their job opportunities to those not retained. This may have a connection with the geo-relation, because all the candidates live in the same neighborhood.

\subsubsection{Negative Changes on the Candidates' Behavior or Attitude}

Although the negative changes of behavior or attitude didn't affect the operation of the units, three units indicated that they could obviously feel that the candidates not retained changed their original work attitudes and behavior. Most of these negative changes are demonstrated on their working performance. For instance, their work attitude was more passive than before, they cared less about their own work performance or even lowered their work efficiency. However, there was no obvious change on their attendance records. Two units said that they turned a blind eye to the negative changes in order to prevent unnecessary conflict.

It is worth noting that three units give cohesion and commitment training courses to their employees. For example, they inform the candidates of the core purposes, ideals, operation conditions and future development of their own organization. These three units also arrange the growth and support courses to teach the disabled about correct work attitude in the DEDP. In addition, two units have set up employee engagement systems, in which, for example, employees take turns to assist others, participate in the meetings and listen to feelings of other people, while the executives have a meeting and dine with the employees and the project manager periodically.

\subsection{Analysis of External Environment}

\subsubsection{Observation Period and Assessment before Deciding the Staff Retention Roster}

Before announcing the staff retention roster, six units observe the candidates for a while to make sure the candidate really corresponds to their needs, and three units carry out an assessment of the candidates' performance, even though the performance is not the only standard to be considered. The three units usually make an overall consideration on such factors as the family status, the degree of cooperation, and so forth. Based on the interview results, it's not difficult to find that most of the units have an observation period or an assessment system for their candidates. However, working performance is not the only assessment standard because the candidates are physically or mentally disadvantaged with weaker working ability than workers in a normal workplace. As a result, the units take the candidates' family status into overall assessment.

\subsubsection{Factors and Reasons Considered When Selecting the Candidates}

Based on the interview results, ten units pay great attention to degree of cooperation and work attitude and they also consider such minor factors as working atmosphere, working ability, family status, age, and educational background, when selecting candidates. Because the original intention of the DEDP is to assist the disadvantaged, most of the hiring units do not consider age and educational background too much. However, 
one hiring unit indicates that the age factor must be considered owing to its heavier physical work contents. In contrast, several units indicate that they will make an overall consideration and won't single out any particular factor when screening the qualifications to retain a candidate.

\subsubsection{Timing of Announcing the Staff Retention Roster}

Among the twelve units, eight units announce the name list at the late stage of the program, and one unit announces the name list right after it knows what candidates to retain for the next year. According to the interview results, we can find that no matter which type of program the hiring units apply for or what kind of businesses they are involved in, most of them announce the name list at the late stage of the program. The reasons may be that they have to make sure that their programs next year pass the verification system and the number of the candidates they can retain, and they worry that an earlier announcement may negatively affect the performance of the candidates or even cause friction. However, it is found that the timing of announcing the staff retention roster has no connection with Moral Hazard. Our research results show that Moral Hazard didn't happen to a unit that announced the name list at the early stage of the program, and on the contrary, four units announcing the name list at the late stage of the program suffered from Moral Hazard problems.

\subsubsection{Ways to Announce the Staff Retention Roster}

Based on the interview results, it is found that all the units announce the name list either publicly or privately. Two units announce the name list publicly, and five units announce the name list privately. Among the five units adopting private announcement, two tell each candidate in person separately. However, Moral Hazard may happen in either of the announcement ways. Our research results show that a unit announcing the name list publicly didn't suffer from Moral Hazard problems at all, while three units announcing the name list privately did have Moral Hazard issues. In conclusion, it may help lower the possibility of Moral Hazard if public announcement of the name list is adopted.

\subsection{Moral Hazard Situation of the Candidates}

According to the above-mentioned analysis results, Moral Hazard of the candidates isn't serious in all the hiring units. Only four different units have witnessed that the candidates show negative changes in work attitude and working performance after the announcement of staff retention roster. However, those changes have not harmed other people, influenced the working atmosphere, or caused serious disturbance to the operation of the hiring units.

Based on the above results, we conclude that when the candidates know they are not on the staff retention roster and no matter how much effort they make, they cannot change the final results. Then, Moral Hazard may emerge. Nevertheless, the probability of Moral Hazard happening in the units of DEDP isn't high. It is a phenomenon very much different from the theory we infer. 


\section{Conclusions}

Under the rational decision theory, when the employees find that no matter how hard they are working, they still won't be retained in the end, Moral Hazard may happen as a result. The paper defines Moral Hazard as the risk in which candidates change their work attitude or lower their performance, causing negative impact to the hiring organizations after they announce the staff retention roster or the candidates know that they aren't on the staff retention roster in advance.

The authors try to discuss Moral Hazard in theoretical point of view in the paper, and suggest some concrete and feasible proposals on human resources management to help the DEDP achieve its purposes more effectively. However, there are still some research limitations of this paper, like: The units are only located in Yunlin, Chiayi, and Tainan, and it may has the representative problem. The region of the units is too close to represent the overall conditions of the units implementing DEDP in Taiwan. Besides, the original respondents should be the candidates in those units, but they won't descript the real situation in concretely. Therefore, the authors choose to the involved people to get the real information.

Under the rational decision theory, the person in charge of the hiring organization or its manager will prevent Moral Hazard from happening as possible as they can. Nevertheless, in real situations, after interviewing twelve organizations, we find that Moral Hazard exists in four organizations, but the problem isn't so serious or obvious. After analyzing the interview results, we can come to three conclusions: 1) Moral Hazard in the organizations implementing the DEDP isn't obvious, and it won't affect the operation of those organizations seriously. Among the twelve interviewed organizations, only four organizations have the situation in which their candidates change their original behavior and attitude after they know they will not be retained, but the degree of the change won't influence the operation of the organizations. 2) The incidence of Moral Hazard may have a connection with the characteristic of the organizations but has little relevance to their property. Among the twelve organizations, four organizations engaged in volunteer service and having a harmonious working atmosphere don't have Moral Hazard problems and their candidates are even willing to give up their own job opportunities to those not on the retention list after the announcement of the staff retention roster. Meanwhile, the other four organizations with Moral Hazard problems are different in property. 3) The timing of announcing the staff retention roster may not affect the possibility that Moral Hazard happens to the organizations but the way to announce the staff retention roster may influence the possibility that Moral Hazard happens. A majority of the organizations announce their retention name lists at the late stage of the program. The only organization that announces the retention name list in August doesn't suffer from Moral Hazard. In contrast, among all the organizations announcing the name list at the late stage of the program, only four organizations have Moral Hazard problems, while the rest don't have such problems. Most of the organizations inform their candidates of retention results individually and privately but several organizations announce the name list in public. Among the four organizations which suffer from Mora Hazard, three announce the name list individually and privately. 


\section{References}

[1] Lin, Y.J., Wang, Y.D. and Lee, P.F. (2009) 2006 Overall Implementation Benefit Assessment Report of the Diverse Employment Development Program. The 2007 Commissioned Research Projects of CLA Training Bureau of the Executive Yuan, Taipei.

[2] Lan, K.J., Wu, C.H. and Ma, T.C. (2012) The Investigation Plan for the Retaining Situation of the Diverse Employment Development Program. The Commissioned Research Projects of CLA Training Bureau of the Executive Yuan, Taipei.

[3] CLA Training Bureau of the Executive Yuan (2011) The Plan Work Book for the NonGovernmental Groups of the Diverse Employment Development Program. Job Training Bureau, CLA of the Executive Yuan, Taipei.

[4] Lan, K.J. (2014) Developing Social Enterprises to Create Local Employment: Focus on the Diverse Employment Development Program in Taiwan. Taiwan Labor Quarterly, 38, 24-29.

[5] Yu, S.R. (2008) The Investigation on the Transfers of Diverse Employment Development Program to Social Enterprises. Master Thesis, Feng Chia University, Taichung.

[6] Wu, C.H., Lan, K.J. and Ma, T.C. (2013) The Investigation Plan for the Retaining Situation of the Diverse Employment Development Program in Yunlin, Chiayi, and Tainan. The Commissioned Research Projects of Yunlin-Chiayi-Tainan Regional Branch of CLA Training Bureau of the Executive Yuan, Tainan.

[7] Zhu, R.R. and Tong, X.Z. (2005) The Third Sector and the Employment Promotion: The Review of the Diverse Employment Development Program in Ping Tung. Bulletin of Labour Research, 17, 75-111.

[8] Liande Industry and Commerce Development Foundation (2005) The 2003 Assessment and Evaluation Plan of Diverse Employment Development Program. CLA Training Bureau of the Executive Yuan, Taipei.

[9] Lan, K.J. and Wu, C.H. (2014) The Investigation Plan for the Output Value of the Diverse Employment Development Program. The Commissioned Research Projects of MOL Workforce Development Agency of the Executive Yuan, Taipei.

[10] Liu, L.J., Wang, M.S., Huang, G.L., Wang, D.P. and He, B.J. (2009) The Evaluation of the Diverse Employment Development Program in Kaohsiung: Analysis from the Diverse Employment Organizations' Point of View. Bulletin of Labour Research, 25, 1-56.

[11] Lu, C.R. (2014) The Research on Social Enterprises Developed from Non-Profit Organizations in Hualien: A Case of the Diverse Employment Development Program. Master Thesis, Dong Hua University, Hualien.

[12] Wu, C.H. (2015) The Preview and the Review of Diverse Employment Development Program. Working Paper.

[13] Liang, H.W. (2012) The Diverse Employment Development Program's Retention SystemEmployment Patterns, Trends and Opportunities in the Older Population. Employment Security, 11, 80-85.

[14] Huang, K.S. (2011) The Investigation on Human Resource Utilization and Benefit Evaluation of the Diverse Employment Development Program. Employment Security, 10, 58-66.

[15] Liu, Z.C. (2011) The Participation and Observation of the Diverse Employment Development Program. Employment Security, 10, 96-100.

[16] Pindyck, R.S. and Rubinfeld, D.L. (2014) Microeconomics. 8th Edition, Pearson Education, New Jersey. (Y.L. Liu Transfer in Chinese, Hwa Tai, Taipei.)

[17] Chen, J.C. and Lin, H.L. (2013) Microeconomics. Yeh Yeh Book Gallery, Taipei. 
[18] Foster, A.D. and Rosenzweig, M.R. (1994) A Test for Moral Hazard in the Labor Market: Contractual Arrangements, Effort, and Health. The Review of Economics and Statistics, 76, 213-227. http://dx.doi.org/10.2307/2109876

[19] Gautier, P. and Bas van der Klaauw, B.V.D. (2012) Labor Market Policy and Participation over the Life Cycle, Network for Studies on Pensions, Aging and Retirement. Tilburg University, Holland. 


\section{Appendix: The Interview Outline}

\begin{tabular}{|c|c|c|}
\hline Issue & Topic & Outline \\
\hline $\begin{array}{l}\text { To discuss whether the different } \\
\text { characteristic of the units will } \\
\text { influence the possibility of } \\
\text { Moral Hazard from the candidates. }\end{array}$ & $\begin{array}{l}\text { The influence on the possibility } \\
\text { of Moral Hazard to the } \\
\text { characteristic of the units. }\end{array}$ & $\begin{array}{l}\text { 1. Where is your located counties and Villages } \\
\text { and towns to implemented DEDP? } \\
\text { 2. What is your main product and service of DEDP? }\end{array}$ \\
\hline $\begin{array}{l}\text { To discuss whether the content } \\
\text { of the program and the characteristic } \\
\text { of the candidates will influence the } \\
\text { possibility of Moral Hazard. }\end{array}$ & $\begin{array}{l}\text { The influence on the possibility } \\
\text { of Moral Hazard to the content } \\
\text { of the program and the } \\
\text { characteristic } \\
\text { of the candidates. }\end{array}$ & $\begin{array}{l}\text { 1. How many candidates are retained from the program } \\
\text { in your organization currently? } \\
\text { 2. What factors and reasons are considered when } \\
\text { your organization select the candidates? } \\
\text { 3. How long is the observation period before the staff } \\
\text { retention roster is decided? What key points do } \\
\text { your organization pay attention to? }\end{array}$ \\
\hline $\begin{array}{l}\text { To discuss whether the timing } \\
\text { and the way to announce the staff } \\
\text { retention roster will bring out } \\
\text { Moral Hazard from the candidates }\end{array}$ & $\begin{array}{l}\text { The timing and the way to } \\
\text { announce the staff } \\
\text { retention roster. }\end{array}$ & $\begin{array}{l}\text { 1. When does your organization announce the staff retention roster? } \\
\text { 2. What does your organization considered to announce } \\
\text { the staff retention roster at this timing? } \\
\text { 3. What way does your organization use to announce the } \\
\text { staff retention roster? } \\
\text { 4. What does your organization considered to announce } \\
\text { the staff retention roster in this way? }\end{array}$ \\
\hline $\begin{array}{l}\text { To discuss whether there is } \\
\text { Moral Hazard in the units } \\
\text { implementing the DEDP } \\
\text { and its extent of severity. }\end{array}$ & $\begin{array}{l}\text { After announce the staff } \\
\text { retention roster, the difference } \\
\text { in the candidates and the } \\
\text { extent of influence to the } \\
\text { operation of the units. }\end{array}$ & $\begin{array}{l}\text { 1. After knowing they weren't be retained, whether there is } \\
\text { Changes of attitude or behaviors among candidates? } \\
\text { 2. If yes, what are those obvious changes on their behavior or attitude? } \\
\text { 3. Whether these changes on their behavior or attitude affect } \\
\text { the operation? } \\
\text { 4. Whether there are situations in which candidates guess or ask } \\
\text { about the staff retention roster? If yes, when did it happen? } \\
\text { their original work attitudes or lower their working performance? } \\
\text { 6. If yes, what are these obvious difference? }\end{array}$ \\
\hline
\end{tabular}

Scientific Research Publishing

Submit or recommend next manuscript to SCIRP and we will provide best service for you:

Accepting pre-submission inquiries through Email, Facebook, LinkedIn, Twitter, etc.

A wide selection of journals (inclusive of 9 subjects, more than 200 journals)

Providing 24-hour high-quality service

User-friendly online submission system

Fair and swift peer-review system

Efficient typesetting and proofreading procedure

Display of the result of downloads and visits, as well as the number of cited articles

Maximum dissemination of your research work

Submit your manuscript at: http://papersubmission.scirp.org/

Or contact me@scirp.org 